\title{
Environmental context influences visually perceived distance
}

\author{
JOSEPH S. LAPPIN \\ Vanderbilt University, Nashville, Tennessee \\ AMY L. SHELTON \\ Johns Hopkins University, Baltimore, Maryland \\ and \\ JOHN J. RIESER \\ Vanderbilt University, Nashville, Tennessee
}

\begin{abstract}
What properties determine visually perceived space? We discovered that the perceived relative distances of familiar objects in natural settings depended in unexpected ways on the surrounding visual field. Observers bisected egocentric distances in a lobby, in a hallway, and on an open lawn. Three key findings were the following: (1) Perceived midpoints were too far from the observer, which is the opposite of the common foreshortening effect. (2) This antiforeshortening constant error depended on the environmental setting-greatest in the lobby and hall but nonsignificant on the lawn. (3) Context also affected distance discrimination; variability was greater in the hall than in the lobby or on the lawn. A second experiment replicated these findings, using a method of constant stimuli. Evidently, both the accuracy and the precision of perceived distance depend on subtle properties of the surrounding environment.
\end{abstract}

Space is a ubiquitous aspect of everyday experience. Spatial frameworks organize our awareness, actions, and memories. Concepts of space are fundamental for theories of perception and action, but developing adequate concepts of perceived space may be "the first and final frontier" for perceptual theory (Turvey, 2004).

Everyday experience suggests that visually perceived space is both accurate and precise. Forces of successful actions must fit goal distances, without systematic underor overshooting. Indeed, even blindfolded locomotion to previously seen targets tens of meters away usually exhibits little or no systematic error (Rieser, Ashmead, Talor, \& Youngquist, 1990; Rieser, Holman, Cummins, Weingarten, \& Ridley, 2004; Rieser, Pick, Ashmead, \& Garing, 1995).

Systematic errors often occur, however, in settings with ambiguous or unfamiliar reference frames. Classic examples include the Ames room (Ittelson, 1952) and the moon illusion (Kaufman \& Rock, 1962a, 1962b; Minnaert, 1993). As in the moon illusion, a reference frame

This research was supported in part by NIH Grant R03EY015558 to J.S.L., NSF Grant IIS-0121038 to J.J.R., and NIH Vision Core Grant P30EY08126. The authors are grateful to many observers who volunteered to help with this study, to Dawn Williams for help in both setting up and conducting the experiments, to Jeffrey Oliver for help in collecting data, to Duje Tadin for help in designing Figure 3, and to Dennis Proffitt and two anonymous reviewers for their suggestions on an earlier draft. Correspondence concerning this article should be addressed to J. S. Lappin, Vanderbilt Vision Research Center, Department of Psychology, Vanderbilt University, 301 Wilson Hall, Nashville, TN 37203 (e-mail: joe.lappin@vanderbilt.edu). for perceiving distance is often lacking for objects seen against the sky. Thus, a small radio-controlled drone plane may be misperceived as a distant, normal-sized plane flying at an impossibly high speed (Hershenson \& Samuels, 1999). When "jumbo jets" were new and pilots were not yet accustomed to the increased eye height, they sometimes collided with the terminal, underestimating their approach speed.

An extensive experimental literature has demonstrated that visually perceived space is prone to both systematic and variable errors, as has been described in many reviews (e.g., Baird, 1970; Cutting \& Vishton, 1995; Foley, 1978; Foley, Ribeiro-Filho, \& Da Silva, 2004; Hershenson, 1999; Howard \& Rogers, 2002; Indow, 1997; MacLeod \& Willen, 1995; Norman, Todd, Perotti, \& Tittle, 1996; Sedgwick, 1986; Suppes, 1995; Suppes, Krantz, Luce, \& Tversky, 1989; Todd \& Norman, 2003). Despite the extensiveness of both the experimental and the theoretical literature, however, many basic properties of perceived space remain uncertain. Different studies yield different results, influenced by unidentified stimulus and task conditions.

The diversity of results is exemplified by studies of perceived egocentric distance (of objects from the observer). Some studies have shown that distances can be perceived both accurately (with little systematic error) and precisely (with little variability). Rieser et al. (1990), for example, had observers view targets at 2- to 22-m distances in an open field and then walk blindfolded to the target location. Constant errors averaged only about $2 \%$, independently of distance. Variable errors averaged about $8 \%$, which 
might be considered small for these responses. Loomis, Da Silva, Philbeck, and Fukusima (1996) reported similar results from several experiments in which blindfolded observers walked to a previously seen target or triangulated the target location by pointing to it while walking in a different direction. Purdy and Gibson (1955) reported that observers could accurately bisect and trisect distances up to $270 \mathrm{~m}$ in an open field, with an average constant error of only about $3 \%$. Rieser et al. (1990) also replicated this result with 2- to 24-m distances.

Other studies, however, have shown that depth judgments exhibit systematic foreshortening - increasing underestimation of depths at greater distances. One example is a study by Gilinsky (1951), who found that bisected egocentric distances in an open field were a compressive nonlinear function of physical distance. Constant errors reached $40 \%$ at target distances of only $60 \mathrm{~m}$. Comparable errors are found when observers match apparent depth separations in the sagittal plane with those in the frontal plane (Loomis, Da Silva, Fujita, \& Fukusima, 1992). Beusmans (1998) reported similar results, and hypothesized that visual foreshortening of the ground plane derives from image velocities of optic flow during locomotion. ${ }^{1}$ The striking discrepancy between such visual foreshortening and the accurate judgments found by Purdy and Gibson (1955), Rieser et al. (1990), and Loomis et al. (1992; Loomis et al., 1996) remains unexplained.

Visual foreshortening might seem a natural result of the proportional increase in image compression with increasing viewing distance. Traditional conceptions of visual space often assumed that two-dimensional (2-D) metric image separations constitute the retinal input for spatial vision, but very little evidence actually supports this assumption.

The common intuition that perceived space is Euclideanthat is, invariant with changes in the observer's viewing position - has been repeatedly contradicted by experimental evidence (e.g., Foley, 1972; Foley et al., 2004; Koenderink, 2001; Koenderink, van Doorn, \& Lappin, 2000; Loomis et al., 1996; Norman \& Todd, 1993; Norman, Lappin, \& Norman, 2000; Norman et al., 1996; Todd \& Norman, 2003; Toye, 1986; Wagner, 1985). In Wagner and in Loomis et al. (1992), for example, perceived relative distances between objects in an open field were compared, and both studies showed that separations in the sagittal plane appeared to be only about $50 \%-70 \%$ as large as physically equal separations in the frontal plane. Such systematic and variable errors occur even in full-cue conditions in natural environments. Not surprisingly, spatial judgments usually are less accurate and less reliable under impoverished viewing conditions (e.g., Loomis et al., 1996).

Perceptual resolution is also lower for distances in depth than for those in the frontal plane. For smaller distances, just beyond arm's reach, Norman et al. (1996) found that Weber fractions for relative length increased from $2 \%$ to $3 \%$ for parallel lines in the frontal plane to almost 30\% for three-dimensional (3-D) lengths at different orientations in depth. They also found that judged lengths in depth decreased with increasing viewing distance.
Visual space was classically conceived as an abstract structure independent of its contents. Environmental context often was regarded as either irrelevant or a source of indirect "cues" for size and distance. To eliminate unwanted environmental effects, experimenters often presented just a few points of light in a darkened room (Suppes et al., 1989). The assumption that visual space is context invariant may be mistaken, however. Indow $(1991,1997)$ and Suppes (1995) have concluded that visual space is context dependent. If perceived spaces are altered by the objects they contain, understanding such effects is necessary for an adequate theory of space perception. Evidence about environmental context effects is limited, however.

Recent evidence suggests that visual depth is scaled partly by the ground plane. Sinai, Ooi, and He (1998) demonstrated that perceived distances were reduced by ground plane discontinuities - by a spatial gap or a textural change. $\mathrm{Wu}$, Ooi, and $\mathrm{He}(2004)$ varied the area and location of visible regions of the ground plane and concluded that egocentric distances are perceived by visually integrating local patches of the ground. If visual depth depends on the ground plane, perhaps it is also influenced by other visible surfaces.

In the present study, we investigated discriminations of relative egocentric distances in three different but familiar natural settings. The surface layouts differed between these settings, although the surfaces in all three were predominantly planar and parallel to the viewing direction, with predominantly rectilinear contours. We discovered that perceived spatial relations differed between these environmental contexts in ways not anticipated in the currently available literature.

This study was initially motivated by the unexpected results of a class demonstration. During a seminar discussion of the contrasting results of Gilinsky (1951) and Purdy and Gibson (1955), we decided to demonstrate for the students the bisection procedure used in those studies. Six class members stood at one end of the lobby of Vanderbilt's psychology building, and another six stood facing them $30 \mathrm{~m}$ away, near the other end of the lobby. One group bisected the egocentric distance to the other group by verbally positioning another person to the apparent midpoint, and the procedure was then repeated for the other group in the reverse direction. We had expected these judgments to be either accurate or foreshortened.

The bisections by these two groups of observers were very different, however; each group's judgment appeared foolish to the other group. To our added surprise, the discrepancy was the opposite of the common foreshortening effect. For each group, the apparent midpoint was about $2 \mathrm{~m}$ beyond the true midpoint. A far interval of about $13 \mathrm{~m}$ appeared to be equal to a near interval of $17 \mathrm{~m}$. The illusion was robust - experienced by every student and both instructors, across repeated trials, across variations in positions and distances, and after the observers were aware of their errors. This lobby was not a simple rectilinear box, but the potential cause of these misperceptions was not apparent to any of the observers. 
Because this phenomenon contrasted with previous results, including those of Rieser and colleagues (e.g., Rieser et al., 1990), we decided to investigate its generality and reliability. The structure of two additional settings was less complex. One setting was a large open lawn in front of the psychology building, and another was a long office corridor within the building. Photographs of the three environments are shown in Figure 1. All three settings were familiar to the observers, were fully illuminated, and offered familiar sizes and structural regularities.

In two experiments, different methods were used to assess both constant and variable errors in bisecting egocentric distances. The differences in perceived distances in these three natural environments pose challenging questions about how visual space is scaled by its contents.

\section{EXPERIMENT 1 Bisecting Perceived Distances by a Method of Adjustment}

The purpose was to replicate our informal observations in the lobby and to compare distance discriminations across different environmental contexts. Observers judged the midpoint of an interval extending from their feet to a target person (one of the experimenters) standing either 15 or 30 m away. Judgments were made by verbally instructing an adjustment person to move to the perceived midpoint.

\section{Method}

Environmental settings and experimental design. Three environmental settings were used in or near Vanderbilt's psychology building: the lobby, a hall, and the open lawn in front of the building. The lobby, shown in Figure 1A, measured approximately $42 \mathrm{~m}$ in length and was $5.4 \mathrm{~m}$ wide and $4.7 \mathrm{~m}$ in height. Large windows were regularly spaced on one side (west), and columns, broad stairs, and banisters were centered on the opposite side. Each end of the lobby was a semicircular lounge area with a slightly lower ceiling, and entryways and planters on the west side were near both ends. The floor of the lobby was carpeted, with large rectangular and diamondshaped sections marked by color variations. The length of the lobby was essentially mirror symmetrical around its midpoint. It offered abundant linear perspective, texture, and familiar sizes. The lobby was structurally more complex than the other two settings, but it did not appear in any way strange or confusing and was familiar to all the observers.

The hall, shown in Figure 1B, was approximately $76 \mathrm{~m}$ long, $1.8 \mathrm{~m}$ wide, and $2.6 \mathrm{~m}$ high. A stairway was at the middle, and testing was done in a section between the stairway and the end of the hall. A clear linear perspective was provided by edges of the floor, walls, and ceiling, and scaling was also provided by floor tiles.

The lawn, shown in Figure 1C, was bordered on the east by a low wall in front of the psychology building and by sidewalks on the other sides. It was approximately $55 \mathrm{~m}$ long between sidewalks to the north and south and $48 \mathrm{~m}$ wide from the wall to the west sidewalk, and it extended at least $30 \mathrm{~m}$ beyond the sidewalks before reaching another building. Trees were all well beyond the testing area. The grass offered a visible texture gradient.

Two different distances, 15 and $30 \mathrm{~m}$, were used in each environmental setting. Two different viewing directions were also used in each setting, one in which the observer faced north and one in which he or she faced south. Each observer performed the bisection task twice at each viewing direction for each distance interval, one with the experimenter walking away and one toward the observer. Each observer made 24 judgments: 3 contexts $\times 2$ distances $\times 2$ viewing directions $\times 2$ trials. The order of the three contexts and the order of conditions within each context were varied across observers, and the order of conditions within a context was held constant across contexts for each observer. Following the midpoint adjustment on each trial, its distance from the target person was measured with a Sonin 250 electronic sonic measuring device.

Procedure. The observers were instructed to identify the midpoint on the basis of their perception, without using cognitive strategies, such as counting doors, windows, steps of the adjustment person, and so forth. The observers reported that they had not used such strategies. ${ }^{2}$

For a given pair of trials, one of the experimenters (the adjustment person) positioned the observer at the appropriate end of the linear test interval, and then the other experimenter (the target person) used the sonic measuring device to position him/herself at the appropriate distance $(15$ or $30 \mathrm{~m})$ at the other end. ${ }^{3}$ The adjustment person then walked away from the observer until told by the observer to stop at the apparent midpoint to the target person, with adjustments back and forth as desired by the observer. The target person then measured and recorded his or her own distance from the adjustment person. The second trial began with the adjustment person facing the observer from the target person, and the adjustment person then walked toward the observer. This procedure continued until all eight trials in a given setting were complete. The observers, endpoints, and midpoints were located asymmetrically along the long axis within each environmental setting and varied about $1-3 \mathrm{~m}$ between successive pairs of trials, in an effort to reduce the observers' cognitive reliance on external landmarks and the potential tendency simply to repeat responses from previous trials. All three contexts were tested in a single session.

In addition to these quantitative judgments, the observers were asked, at the end of the session, to rate both the relative difficulty and the confidence of their judgments in the three contexts and to describe any strategies that they may have used.

Observers. Eight observers ( 7 male, 1 female) participated in the experiment. Four were graduate students, 3 were undergraduate summer school students participating for course credit, and 1 was a coauthor.

\section{Results}

For each condition, Table 1 shows the constant errors and variable errors for each condition. The constant error was defined as $\mathrm{CE}=$ judged - correct midpoint distances, in meters for individual observers, and as percentages of the correct midpoint distance for the average over observers. The variable error was computed as a Weber fraction, given by the coefficient of variation, $S D / M$, for each observer's four judgments in a given condition. The average Weber fraction was computed as the RMS (square root of the mean squared value) of the eight individual coefficients of variation. The magnitude of the $\mathrm{CE}$ relative to the variability is given by the standard score, $z=\mathrm{CE} / S D$, for each individual and by the $t$ ratio for the entire group (the average $\mathrm{CE}$ divided by the between-subjects standard error of the mean). Figure 2 shows the normalized CE and Weber fraction for each of the six conditions. As may be seen, the environmental context affected both constant errors and variability, with different effects on each.

Constant errors. The observers reliably overestimated the distance of the midpoint in the lobby and (to a lesser extent) in the hall. Expressed in relation to the correct midpoint and averaged over the two target distances, the CEs for the lobby, hall, and lawn were $13.0 \%, 8.0 \%$, and $3.2 \%$, respectively. The $t$ ratios were statistically signifi- 

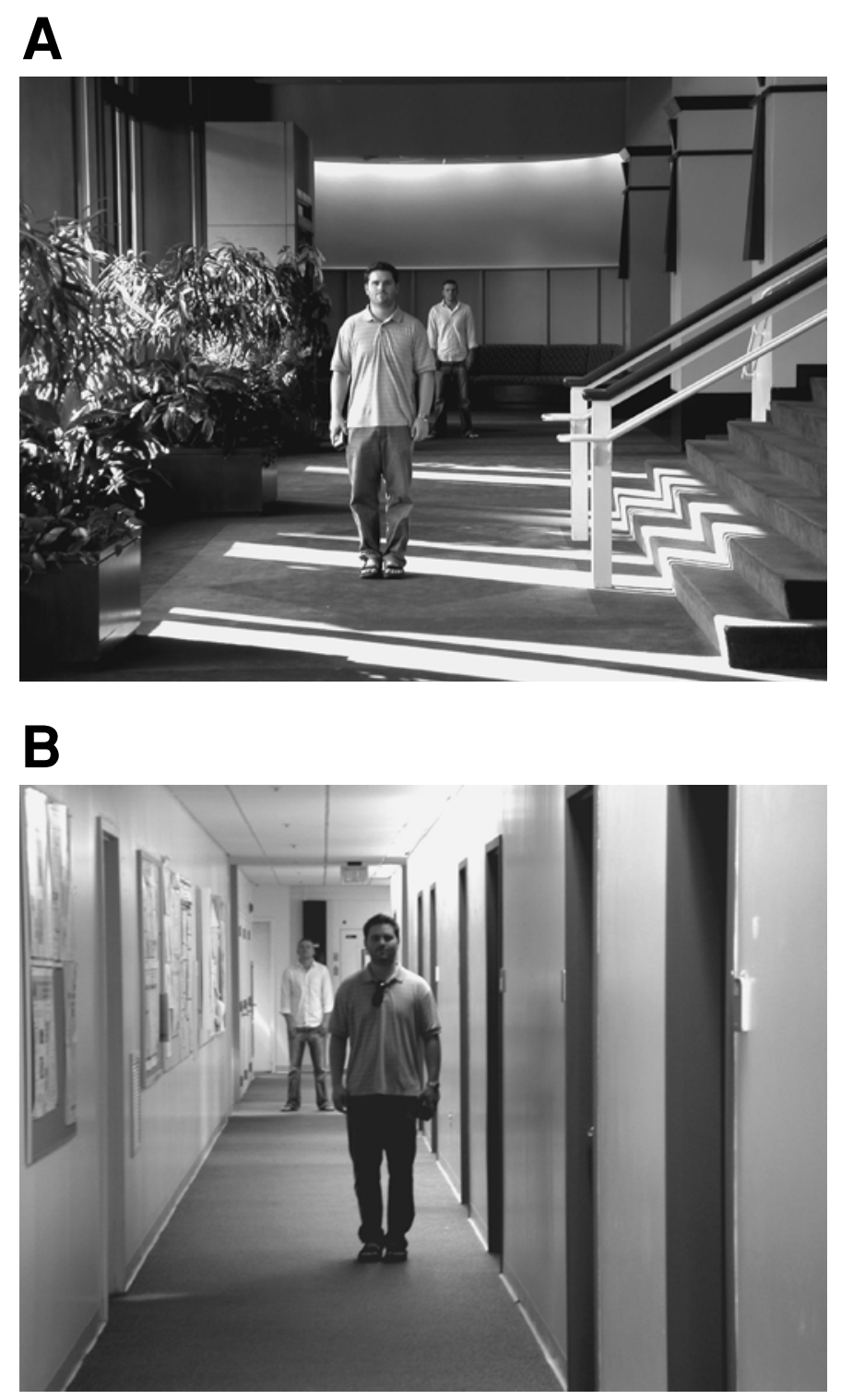

Figure 1. Photographs of the three environmental settings: (A) lobby, (B) hall, and (C) lawn. The people in these photos are 15 and $30 \mathrm{~m}$ from the camera. Note that apparent depths depend partly on perspective - on lens focal length and image expanse. The focal lengths were similar but not identical in these three photos, and neither focal length nor image expanse could be equated to those of human vision.

cant (CEs were significantly different from 0 ) for both the 30 - and the $15-\mathrm{m}$ distances, in both the lobby $[t(7)=14.70$ $(p<.001)$ and $7.19(p<.001)$, respectively] and the hall $[t(7)=4.43(p<.01)$ and $5.32(p<.01)]$. Corresponding $t$ ratios for the lawn were not statistically significant $[t(7)=1.32$ and 1.36]. The effects were also indicated by the numbers of positive CEs for the individual observers in the three environmental contexts: $16 / 16$ for the lobby, $15 / 16$ for the hall, and 12/16 for the lawn.

A repeated measures ANOVA with factors for context (lobby, hall, or lawn), distance (30 or $15 \mathrm{~m}$ ), viewing posi- tion (north or south), and direction (toward or away) was applied to the relative bisection errors (errors as percentages of the true midpoint distances). Only the main effect for context was significant $[F(2,14)=12.86, p<.01]$. Pairwise comparisons showed that only the difference between the lobby and the lawn was significant.

Variable errors. The observers' precision in discriminating distance was measured by the coefficient of variation: $S D / M$, where $M$ and $S D$ are the mean and standard deviation of the four judgments by a given observer at a given distance in a given setting. This is a Weber fraction, 


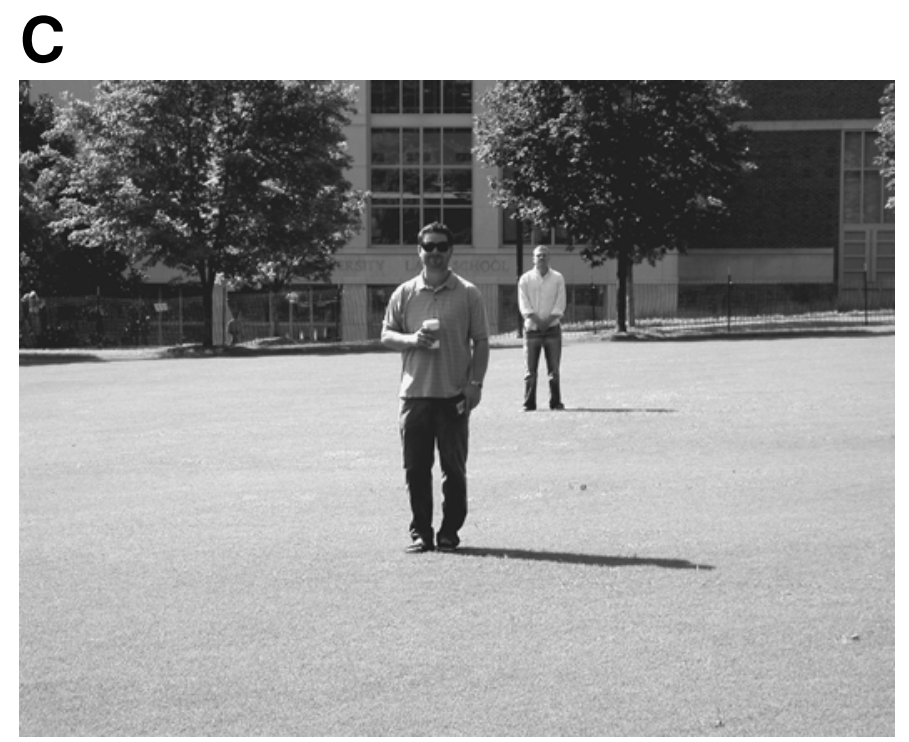

Figure 1 (Continued).

a generalized, scale-free measure of discrimination, of perceptual resolution. Weber fractions for the lobby, hall, and lawn were $4.4 \%, 7.2 \%$, and $4.1 \%$, respectively.

A repeated measures ANOVA, with context and distance as factors, showed that only the main effect for context was significant $[F(2,14)=8.31, p<0.01]$. By pairwise comparisons, the lobby and the lawn did not differ, but Weber fractions were significantly greater $(p<.05)$ for the hall than for either the lobby or the lawn. For all 8 observers at $30 \mathrm{~m}$, Weber fractions were larger for the hall than for either of the other two settings.

The precision of these distance discriminations is impressive by comparison with others reported for small distances in the frontal plane: Weber fractions for the lobby and the lawn were only slightly larger than those found by De Valois, Lakshminarayanan, Nygaard, Schlussel, and Sladky (1990) for discriminating relative positions between 2-D separations on a computer monitor and also were similar to those found by Norman et al. (1996) for discriminating line lengths randomly oriented in the frontal plane. Norman et al. (1996) found much larger Weber fractions for lines randomly oriented in three dimensions.

Subjective difficulty and confidence. In postexperimental reports, 6 of the 8 observers identified the lobby as the easiest location to judge, 1 identified the lawn as easiest, and 1 described the lobby and the lawn as equally easy. Six identified the hall as the most difficult, and the remaining 2 identified the lawn as most difficult. Confidence judgments yielded a similar ordering, with 6 of the 8 observers reporting least confidence for the hall. The reasons given for the ease and confidence for the lobby generally referred to the richness of the cues in that environment, although most observers admitted that they could not explain why it seemed easiest. Several observers attributed the difficulty for the hall to apparently greater distances in this setting, and a few suggested that longer distances actually had been used. ${ }^{4}$

\section{EXPERIMENT 2 \\ Distance Discriminations Using a Constant-Stimulus Method}

Experiment 2 replicated Experiment 1, using a different method and different observers. Perhaps the antiforeshortening effect in Experiment 1 depended somehow on the movements of the adjustment person or on the observer's control of those movements. Perhaps the same misjudgments would not occur with objects at fixed locations, the more typical condition in experiments on space perception. As in Experiment 1, observers judged the relative distances of the test and target persons at $30 \mathrm{~m}$. Here, however, the observer judged whether the test person was nearer or farther from the observer than the midpoint of egocentric distance to the target person.

\section{Method}

Materials and Design. The three environmental settings were identical to those used in Experiment 1, but only the 30-m distance was used. In each environment, a 30-m tape of clear vinyl plastic was placed on the floor or ground, aligned with the surrounding walls, from the center of the observer's feet to the center of the feet of the target person. The middle $14 \mathrm{~m}$ of the tape (midpoint $\pm 7 \mathrm{~m}$ ) was marked in $0.25-\mathrm{m}$ intervals (ranging from 8 to $22 \mathrm{~m}$ ), a total of 57 possible target locations. These markings were not visible to the observer. For each observer, 40 of the 57 locations were selected randomly (with replacement) and presented in a random order. For each observer, the same 40 locations were used in all three environments, with a different random sequence in each, and a different random selection of test locations was used for each observer. Two viewing locations were used in each environment, one at the north end and one at the south end of the interval, with 20 trials at each location. On each trial, the observer judged whether the test person was nearer or farther than the midpoint. 
Table 1

Constant Errors (CEs), Weber Fractions ( $S D / M$, the Coefficient of Variation), and Standard Scores $(z=C E / S D)$ for Each Observer

\begin{tabular}{|c|c|c|c|c|c|c|c|}
\hline & & $\begin{array}{c}\text { Lobby } \\
30 \mathrm{~m}\end{array}$ & $\begin{array}{l}\text { Hall } \\
30 \mathrm{~m}\end{array}$ & $\begin{array}{l}\text { Lawn } \\
30 \mathrm{~m}\end{array}$ & $\begin{array}{c}\text { Lobby } \\
15 \mathrm{~m}\end{array}$ & $\begin{array}{l}\text { Hall } \\
15 \mathrm{~m}\end{array}$ & $\begin{array}{c}\text { Lawn } \\
15 \mathrm{~m}\end{array}$ \\
\hline Observer 1 & $\begin{array}{l}\mathrm{CE} \\
S D / M \\
z\end{array}$ & $\begin{array}{l}2.15 \\
3.3 \% \\
3.79\end{array}$ & $\begin{array}{l}0.50 \\
6.9 \% \\
0.46\end{array}$ & $\begin{array}{c}0.63 \\
5.1 \% \\
0.78\end{array}$ & $\begin{array}{l}0.88 \\
1.8 \% \\
5.99\end{array}$ & $\begin{array}{c}0.91 \\
4.3 \% \\
2.56\end{array}$ & $\begin{array}{c}0.24 \\
6.7 \% \\
0.46\end{array}$ \\
\hline Observer 2 & $\begin{array}{l}\mathrm{CE} \\
S D / M \\
z\end{array}$ & $\begin{array}{l}2.37 \\
3.2 \% \\
4.22\end{array}$ & $\begin{array}{l}0.22 \\
6.8 \% \\
0.21\end{array}$ & $\begin{array}{c}-0.09 \\
1.2 \% \\
-0.48\end{array}$ & $\begin{array}{l}0.87 \\
3.3 \% \\
3.06\end{array}$ & $\begin{array}{c}1.01 \\
2.6 \% \\
4.60\end{array}$ & $\begin{array}{c}0.04 \\
0.9 \% \\
0.48\end{array}$ \\
\hline Observer 3 & $\begin{array}{l}\mathrm{CE} \\
S D / M \\
z\end{array}$ & $\begin{array}{l}1.55 \\
2.6 \% \\
3.62\end{array}$ & $\begin{array}{l}0.43 \\
6.5 \% \\
0.43\end{array}$ & $\begin{array}{c}0.09 \\
2.1 \% \\
0.30\end{array}$ & $\begin{array}{l}0.90 \\
1.8 \% \\
6.09\end{array}$ & $\begin{array}{r}1.05 \\
3.5 \% \\
3.48\end{array}$ & $\begin{array}{c}0.14 \\
2.0 \% \\
0.96\end{array}$ \\
\hline Observer 4 & $\begin{array}{l}\mathrm{CE} \\
S D / M \\
z\end{array}$ & $\begin{array}{l}1.81 \\
2.0 \% \\
5.54\end{array}$ & $\begin{array}{l}0.96 \\
5.6 \% \\
1.06\end{array}$ & $\begin{array}{c}-0.05 \\
1.5 \% \\
-0.24\end{array}$ & $\begin{array}{l}0.86 \\
1.1 \% \\
9.96\end{array}$ & $\begin{array}{r}0.90 \\
3.2 \% \\
3.33\end{array}$ & $\begin{array}{c}0.02 \\
2.1 \% \\
0.11\end{array}$ \\
\hline Observer 5 & $\begin{array}{l}\mathrm{CE} \\
S D / M \\
z\end{array}$ & $\begin{array}{l}1.75 \\
3.5 \% \\
3.01\end{array}$ & $\begin{array}{l}1.81 \\
6.5 \% \\
1.63\end{array}$ & $\begin{array}{c}2.04 \\
2.5 \% \\
4.82\end{array}$ & $\begin{array}{l}0.54 \\
3.7 \% \\
1.77\end{array}$ & $\begin{array}{r}0.73 \\
7.8 \% \\
1.14\end{array}$ & $\begin{array}{r}0.90 \\
3.9 \% \\
2.77\end{array}$ \\
\hline Observer 6 & $\begin{array}{l}\mathrm{CE} \\
S D / M \\
z\end{array}$ & $\begin{array}{c}1.84 \\
0.7 \% \\
15.30\end{array}$ & $\begin{array}{c}1.46 \\
14.0 \% \\
0.63\end{array}$ & $\begin{array}{c}0.06 \\
3.5 \% \\
0.11\end{array}$ & $\begin{array}{c}1.62 \\
13.2 \% \\
1.35\end{array}$ & $\begin{array}{r}0.91 \\
12.5 \% \\
0.87\end{array}$ & $\begin{array}{c}0.29 \\
3.2 \% \\
1.15\end{array}$ \\
\hline Observer 7 & $\begin{array}{l}\mathrm{CE} \\
S D / M \\
z\end{array}$ & $\begin{array}{l}2.51 \\
5.7 \% \\
2.51\end{array}$ & $\begin{array}{l}0.56 \\
9.3 \% \\
0.39\end{array}$ & $\begin{array}{c}-0.73 \\
9.3 \% \\
-0.55\end{array}$ & $\begin{array}{l}0.46 \\
1.0 \% \\
6.01\end{array}$ & $\begin{array}{r}-0.09 \\
1.5 \% \\
-0.79\end{array}$ & $\begin{array}{l}-0.65 \\
2.9 \% \\
-3.16\end{array}$ \\
\hline Observer 8 & $\begin{array}{l}\mathrm{CE} \\
S D / M \\
z\end{array}$ & $\begin{array}{l}2.65 \\
2.9 \% \\
5.05\end{array}$ & $\begin{array}{l}1.52 \\
5.3 \% \\
1.73\end{array}$ & $\begin{array}{c}1.40 \\
3.9 \% \\
2.19\end{array}$ & $\begin{array}{l}1.10 \\
3.3 \% \\
3.86\end{array}$ & $\begin{array}{r}0.41 \\
7.1 \% \\
0.73\end{array}$ & $\begin{array}{r}1.20 \\
4.6 \% \\
2.98\end{array}$ \\
\hline $\begin{array}{l}\text { Average } \\
\text { RMS } \\
\text { Average }\end{array}$ & $\begin{array}{l}\text { CE/Mdpt } \\
S D / M \\
z \\
t(7)\end{array}$ & $\begin{array}{c}13.9 \% \\
3.3 \% \\
5.38 \\
14.70\end{array}$ & $\begin{array}{l}6.2 \% \\
8.1 \% \\
0.82 \\
4.43\end{array}$ & $\begin{array}{r}2.8 \% \\
4.4 \% \\
0.87 \\
1.32\end{array}$ & $\begin{array}{c}12.1 \% \\
5.2 \% \\
4.76 \\
7.19\end{array}$ & $\begin{array}{r}9.7 \% \\
6.3 \% \\
1.99 \\
5.32\end{array}$ & $\begin{array}{r}3.6 \% \\
3.7 \% \\
0.72 \\
1.36\end{array}$ \\
\hline
\end{tabular}

Note-The four rows at the bottom give average errors (CEs) as percentages of the correct midpoint distance, RMS Weber fractions, average $z$ scores, and $t$ ratios $(d f=7)$ for the null hypothesis that $\mathrm{CE}=0 . \mathrm{CE}>0$ represents judgments farther than the true midpoint, and $\mathrm{CE}<0$ represents underestimates.

Procedure. As in Experiment 1, two experimenters served as the target person and the test person. The observer stood at one end of the 30-m tape, and the target person stood at the other end. At the beginning of each trial, the observer turned his/her back to the target person while the test person moved to a particular location on the tape. Once in place, the test person signaled the observer to turn around and decide whether the test person was "near" or "far," relative to the midpoint. The observer also rated his/her confidence, using a numerical rating from 1 for certain to 3 for uncertain. For example, if the observer believed that the test person was definitely nearer than the midpoint, he or she would respond "near 1." The test person recorded the response, and the observer then turned away from the target and test persons. To reduce the likelihood that the observers would rely on environmental landmarks, the target person and the observer switched ends after every 10 trials. During these switches, the endpoints of the tape were also shifted to change the locations within the environment.

Initially, the observers were tested only in the lobby and on the lawn, counterbalanced for order. Following this initial data collection, all the observers came back on a later day and performed the same judgments in the hall.

Observers. Eight observers ( 3 male, 5 female) participated in the experiment. Six were graduate students, and 2 were undergraduates.

\section{Results}

To roughly approximate an equal-interval scale of apparent distance, from definitely near to definitely far, the observers' responses were numerically described as follows: Near $1=-5$, Near $2=-3$, Near $3=-1$, Far $3=1$, Far $2=3$, and Far $1=5.5$

Figure 3 shows the psychophysical relation (averaged over observers) between physical distance and perceived distance for each of the three environments. (Because each observer judged a different random sample of 40 distances, these means involve averages over different sets of observers at each of the 57 target locations.) The psychophysical functions are approximated in this figure by cumulative normal functions. As may be seen, these functions describe data for the lobby and lawn, but the hall data have been artificially fit by adjusting the asymptote at the lower left to -4.5 instead of the true lower limit of -5 . (Without this ad hoc adjustment, many data points deviated visibly and systematically from the curve.) The perceived bisection is given by the distance at which the psychometric function equals the rating of 0 , and the variable error is represented by the standard deviation of the normal ogive.

For the lobby, hall, and lawn, the perceived bisections estimated by these psychophysical functions are at 16.74 , 16.79 , and $15.62 \mathrm{~m}$, respectively, corresponding to constant errors of $11.6 \%, 12.0 \%$, and $4.1 \%$. The standard deviations underlying these normal ogives - reflecting variability both between and within observers - were 1.95, 2.29 , and $2.44 \mathrm{~m}$ for the lobby, hall, and lawn, respec- 

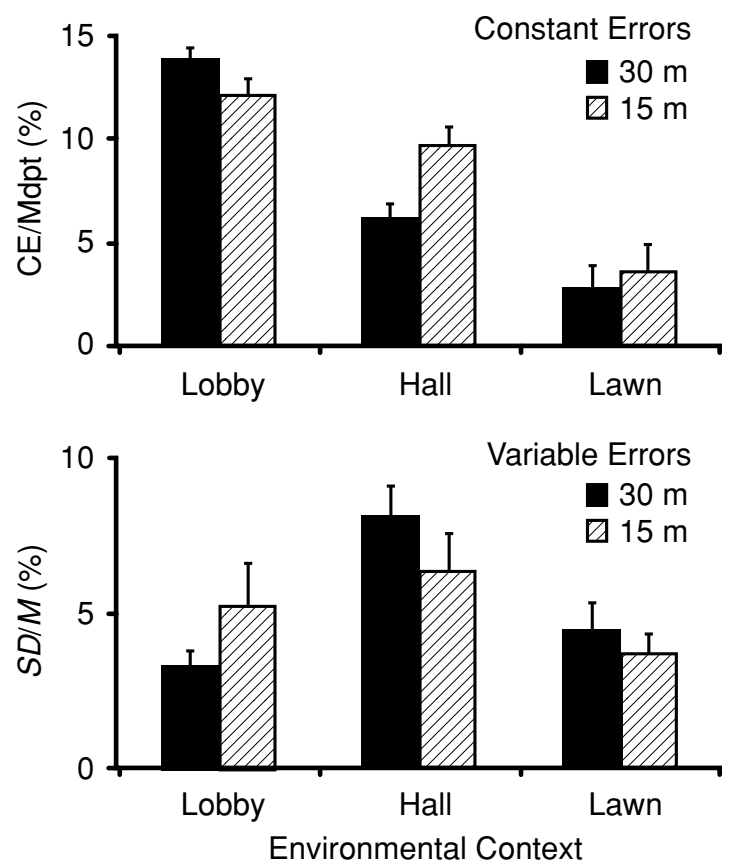

Figure 2. Constant errors (CEs; percentages of the correct values) and variable errors (coefficients of variation) in each of the three environmental contexts. Error bars specify standard errors of the means over 8 observers.

tively. This estimate of variability for the hall is evidently too low, however, as will be indicated by the following analysis.

Better estimates of variability were obtained from the slopes of linear functions describing the intermediate range of distance ratings (between \pm 4.0 ), describing $91 \%-93 \%$ of the variance. The slope of this portion of the psychophysical function (involving both betweenand within-observers variability) is lower for the hall than for either the lobby or the lawn. By these psychophysical slopes, judgments were 1.50 times more variable in the hall than in the lobby and 1.32 times more variable than on the lawn. Variability on the lawn was 1.14 times greater than that in the lobby. We also will report below that the hall produced the least confidence.

One statistical comparison of these psychophysical functions was based on the average distance ratings for the three contexts at each of 24 test locations around the true midpoint, from 12 to $17.75 \mathrm{~m}$. These locations were judged nearest in the lobby and farthest on the lawn. By a Friedman ANOVA of ranks (with $k=3$ conditions and $n=24$ locations), the average distance ratings in this region were reliably different in the three settings $(\mathrm{Fr}=$ $30.08, p<.001$, distributed as $\chi^{2}$ with $d f=2$ ). All three pairwise comparisons were significant $(p<.01$, twotailed) by sign tests: lobby $<$ lawn ( 24 of 24 cases judged nearer in the lobby), lobby $<$ hall ( 18 of 22 cases, excluding ties), and hall $<$ lawn (17 of 20 cases).

Another analysis of perceived distances relative to the apparent midpoint in the three settings was based on the average rating (on the -5 to +5 scale) given by each observer in each setting, averaged across all 40 target locations in each setting. All but 1 of these 24 average ratings (3 settings $\times 8$ observers) were negative - that is, near. Average ratings for the lobby, lawn, and hall were -1.55 , -0.71 , and -1.11 , respectively. These average ratings were reliably different $[F(2,14)=3.83, p<.05]$. By sign test, judged distances (relative to the perceived midpoint) on the lawn were reliably greater $(p<.05)$ than those in the lobby or the hall ( 7 of 8 cases for both), but the latter did not differ consistently.

A similar analysis evaluated confidence in the three environments, using the 3-point rating and ignoring the near versus far judgment. On the 3-point scale, where 1 represented greatest confidence and 3 least confidence, average ratings for the lobby, hall, and lawn were 2.05, 2.26, and 2.12 , respectively, and these means are significantly different $[F(2,14)=5.38, p<.05]$. Confidence in the hall was consistently less than that in the lobby ( 7 of 8 cases), but the other two comparisons were not significant. Lower confidence in the hall corresponds to the greater judgmental variability in this setting.

\section{GENERAL DISCUSSION}

This study demonstrates that both the accuracy and the precision of visually perceived distance are conditioned on the structure of the surrounding visual field. Related context effects associated with the ground plane have been found by Sinai et al. (1998) and Wu et al. (2004), although the present results entail more subtle aspects of the surrounding environment. Such context effects probably contribute to the diversity of empirical findings about perceived space.

Before our unexpected observations in the lobby, we anticipated neither antiforeshortening nor its dependence on environmental context. The phenomenology of moving through spatial environments that seem invariant with our movements has led some scientists (e.g., Gibson, 1950) and most nonscientists to believe that visual space is generally veridical. The intuitive veridicality of visual space had been reinforced by certain experimental results (e.g., Loomis et al., 1992; Purdy \& Gibson, 1955; Rieser et al., 1990). Initially, we expected that judgments of relative distances of familiar objects in natural settings would be easy, accurate, and reliable - as we found for the lawn. To our surprise, judgments in the lobby were easy and reliable but inaccurate, and judgments in the hall were more difficult, inconsistent, and inaccurate.

Three aspects of the results warrant discussion: (1) antiforeshortening constant errors, (2) the meaning of judgmental variability, and (3) the influence of environmental context.

\section{Constant Errors Involving Perceptual Expansion of Space}

A surprising finding was that the perceived midpoint to a distant target was farther than the true midpoint, especially in the lobby. We have called this effect antifore- 

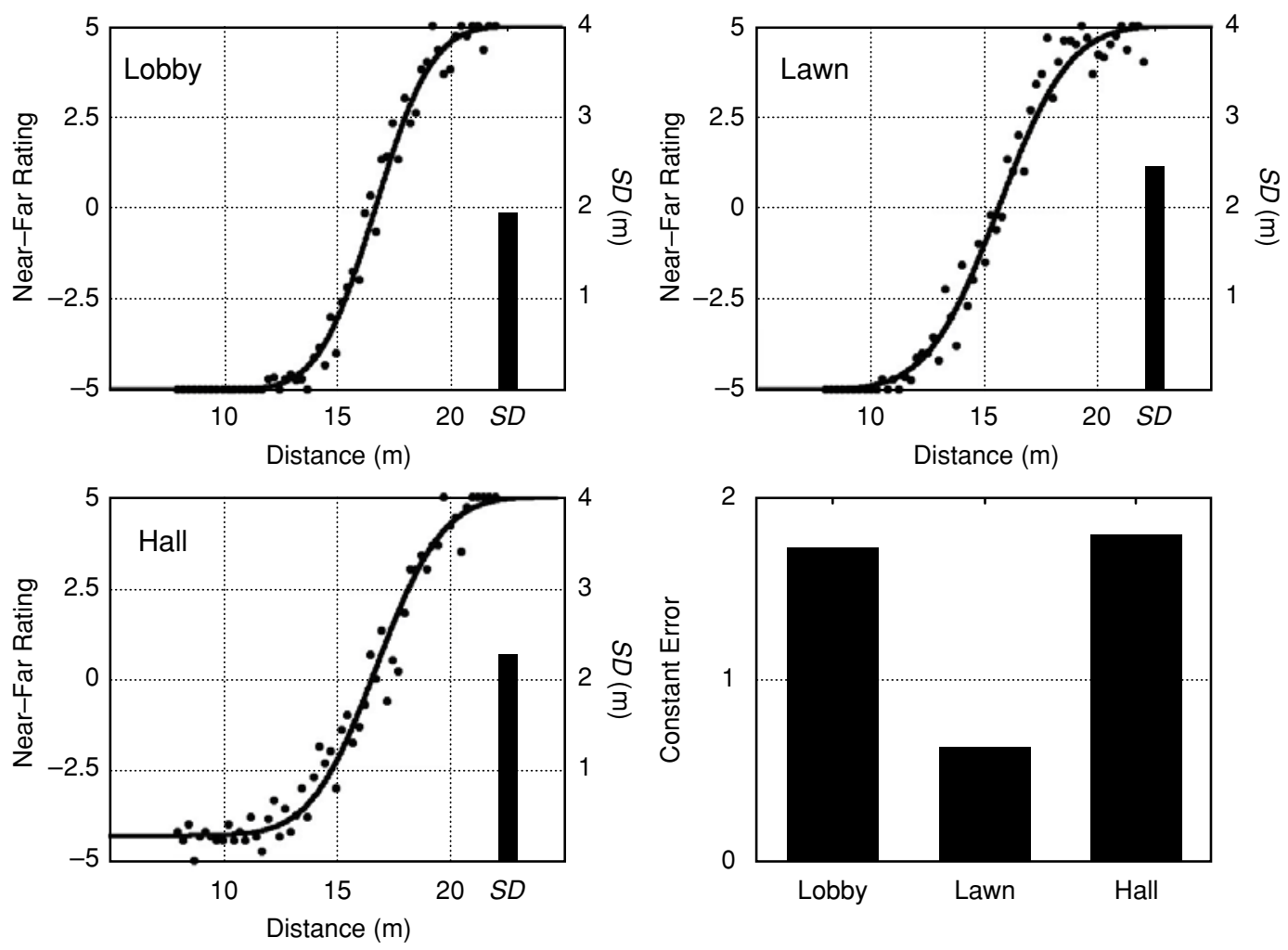

Figure 3. Psychometric functions defined by the average near-far confidence rating (where $\mathbf{- 5}$ designates definitely near and +5 designates definitely far) at each $0.25-\mathrm{m}$ interval (see the text for procedures). The smooth curves are cumulative normal distributions. The underlying standard deviation ( $S D$, in meters) of this distribution is shown in each panel, and the displacement (in meters) of the function from the true midpoint at $15 \mathrm{~m}$ is shown in the lower right panel.

shortening, to contrast it with the so-called foreshortening shown in many previous studies of perceived space (Baird \& Biersdorf, 1967; Beusmans, 1998; Gilinsky, 1951; Harway, 1963; Loomis et al., 1992; Norman et al., 1996; Thouless, 1931; Toye, 1986; Wagner, 1985). Foreshortening sometimes has been considered an inevitable property of visual space, because it corresponds qualitatively to the inverse relation between viewing distance and retinal size, has been found in many different studies, and is easily observed in everyday settings. For example, the dashed lane markings on interstate highways usually appear much shorter in the distance than when close to one's car, and the depth/width aspect ratio of a distant sidewalk section appears much smaller than when the same section is beneath one's feet. Nevertheless, the present experiments demonstrate that visual foreshortening is certainly not universal.

Ours is not the only report of perceptual expansion. Le Grand (1956/1967, p. 236) found this effect in bisecting distances between two targets when the midpoint was less than $15 \mathrm{~m}$ from the observer. His suggestion that such effects might be attributable to the nonlinear relation between depth and binocular disparity would not account for the present context-dependent effects, however. ${ }^{6}$ Norman et al. (2000) found such effects in a study of perceived exocentric lengths between points on cylindrical surfaces. Despite their reduced image sizes, lengths of curves in depth were both overestimated and judged to be longer than equivalent frontal plane lengths, and some observers' estimations increased with viewing distance. Contextdependent expansion of egocentric distance was also reported recently by Riener, Witt, Stefanucci, and Proffitt (2005). Both visual matching and blindfolded walking showed that target distances appeared greater when targets were near the end of a hallway than when farther from the end. Questions remain unanswered, however, about the generality of this perceptual expansion and about the specific conditions in which it occurs.

Surprisingly, we usually have found it easy to demonstrate expansion of perceived distance. For example, a movable object (say a pencil held vertically at eye level) can be positioned so that it appears to bisect the distance to another object. Or an observer can walk from a near object to a distance that appears equal to that between the near and a far object in the same direction. The relative distances so designated usually appear quite different when seen from the side. Small objects on the floor seem to work about as well as objects near eye level, and the effect can be found at various distances in various environments. An intriguing question is why such perceived spatial alterations are so seldom noticed. Koenderink (2001) has described other phenomena suggesting that spatial vision is quite tolerant of such ambiguities and inconsistencies. 
Theoretical explanation poses another challenge. Foley et al. (2004) recently proposed a potentially relevant model of perceived exocentric extents. Their model hypothesizes that visual angles of exocentric extents are perceptually magnified. Accordingly, the size of an object at a true midpoint might be perceptually magnified, relative to that of a farther object, making it appear closer and causing the observer to adjust its position farther than the true midpoint. One problem with this post hoc interpretation is that it conflicts with a perceived reduction of egocentric distances assumed in their model and obtained in their experiment.

One question in applying this and other models to our study concerns possible perceptual differences between egocentric and exocentric distances. The model of Foley et al. (2004) implicitly distinguishes between these two forms of relative distance. Loomis et al. (1992) also concluded that egocentric and exocentric distances might be perceptually dissociated, with egocentric distances accurately perceived and exocentric distances foreshortened. This hypothesis does not seem to fit the present results, however: If distance from the near to the far object is exocentric and that to the near object is egocentric, the exocentric far distance was judged relatively greater than the egocentric near distance. The larger unresolved issue is to identify the frames of reference for perceiving distances in various settings and tasks.

\section{Reliability and Discrimination}

Visual information about space involves discriminationresolution, reliability, and precision - as well as accuracy. Our finding that environmental context had different effects on accuracy and reliability underscores the visual distinction between these two aspects of performance.

The Weber fraction (coefficient of variation in the present study) is a generalized, scale-free measure of discrimination of perceptual information. Weber fractions for bisections in the frontal plane usually are about 1\%-3\% (De Valois et al., 1990; Lappin, Donnelly, \& Kojima, 2001; Lappin \& Fuqua, 1983; Levi \& Klein, 1992). By comparison, the present Weber fractions for bisecting egocentric distance were only slightly larger, averaging $4 \%$ in the lobby and on the lawn but above $7 \%$ in the hall. The lawn seemed to offer fewer depth cues than did the lobby, so the similar discrimination in these two settings is surprising.

The hall offered striking linear perspective, so we were surprised by the imprecision and lower confidence in the hall. Perhaps linear perspective contributes little to the perception of distance. The width of the visual field in the hall (76 m long, $1.8 \mathrm{~m}$ wide, and $2.6 \mathrm{~m}$ high) was restricted by walls on either side, offering an effectively narrower field of view than did either the lobby or the lawn. Perhaps the width of the visual field contributes more to distance perception than has previously been realized.

\section{Context Dependence of Visual Space}

A principal but unanticipated result was that both the accuracy and the precision of perceived distance depended on the environmental context. The idea that visual space is structured by its contents is not new but remains insufficiently understood. Gibson (1950) proposed that "visual space, unlike abstract geometrical space, is perceived only by virtue of what fills it" (p. 5). Similarly, Indow (1991) concluded that visual space "is dynamic, not a solid empty container into which various percepts are put without affecting its contours and intrinsic structure" (p. 450). As Suppes (1995) put it, "the most important general feature of visual space is that it is context dependent, a characteristic of physical systems rather than classical geometrical ones. . . . No reasonably simple set of axioms . . . can be given for the structure of visual space" (p. 37).

The conclusions of Indow (1991) and Suppes (1995) were based on geometric inconsistencies among judgments of multiple spatial relations among multiple objects. The relations among these judgments indicated that visual space changes with attention to different relationships among different objects. The present study offers complementary evidence: Perceptions of even simple spatial relations among familiar objects in familiar settings varied with the environmental context. The scientific challenge is to reveal the nature of such context effects.

The visual field consists of images of surfaces. The three environmental settings in the present study contained quite different arrangements of visible surfaces. A plausible speculation is that the obtained context effects reflected visual structuring of space by the surrounding surfaces. Additional experiments will be required, however, to identify the specific surface properties responsible for these effects.

At least two lines of evidence indicate that visual space is structured by surfaces. Evidence that local surface shape is a visual primitive not derived from simpler image properties was obtained by Lappin and Craft (2000), who found hyperacuities for local surface shape maintained under added noise in lower order image properties. A second line of evidence involving perceived distance is given by the studies of Ooi, He, and colleagues (Sinai et al., 1998; Wu et al., 2004), who found that the ground plane is a visual reference for scaling distances. Such results indicate the visual importance of surface structure, although neither study anticipates or explains the context effects found in the present study. If visual space is indeed structured and scaled by the surfaces it contains, much remains to be learned about such effects.

\section{REFERENCES}

BAIRD, J. C. (1970). Psychophysical analysis of visual space. Oxford: Pergamon.

BAIRD, J. C., \& BIERSDORF, W. R. (1967). Quantitative functions for size and distance judgments. Perception \& Psychophysics, 2, 161-166.

Beusmans, J. M. H. (1998). Optic flow and the metric of the visual ground plane. Vision Research, 38, 1153-1170.

Cutting, J. E., \& Vishton, P. M. (1995). Perceiving layout and knowing distances: The integration, relative potency, and contextual use of different information about depth. In W. Epstein \& S. Rogers (Eds.), Perception of space and motion (pp. 69-117). San Diego: Academic Press. 
De Valois, K. K., Lakshminarayanan, V., Nygaard, R., Schlussel, S., \& SladKy, J. (1990). Discrimination of relative spatial position. $\mathrm{Vi}$ sion Research, 30, 1649-1660.

FOLEY, J. M. (1972). The size-distance relation and intrinsic geometry of visual space: Implications for processing. Vision Research, 12, 323332.

Foley, J. M. (1978). Primary distance perception. In R. Held, H. S. Leibowitz, \& H.-L. Teuber (Eds.), Handbook of sensory physiology: VIII. Perception (pp. 181-213). New York: Springer.

Foley, J. M., Ribeiro-Filho, N. P., \& DA Silva, J. A. (2004). Visual perception of extent and the geometry of visual space. Vision Research, 44, 147-156.

GiBson, J. J. (1950). The perception of the visual world. Boston: Houghton Mifflin.

Gilinsky, A. S. (1951). Perceived size and distance in visual space. Psychological Review, 58, 460-482.

HARWAY, N. I. (1963). Judgment of distance in children and adults. Journal of Experimental Psychology, 65, 385-390.

Hershenson, M. (1999). Visual space perception. Cambridge, MA: MIT Press.

Hershenson, M., \& Samuels, S. (1999). An airplane illusion: Apparent velocity determined by apparent distance. Perception, 28, 433-436.

Howard, I. P., \& Rogers, B. J. (2002). Seeing in depth: Vol. 2. Depth perception. Toronto: Porteous.

InDow, T. (1991). A critical review of Luneburg's model with regard to global structure of visual space. Psychological Review, 98, 430-453.

INDOw, T. (1997). Hyperbolic representation of global structure of visual space. Journal of Mathematical Psychology, 41, 89-98.

Ittelson, W. H. (1952). The Ames demonstrations in perception. Princeton, NJ: Princeton University Press.

Kaufman, L., \& Rock, I. (1962a). The moon illusion: I. Science, 136, 953-961.

Kaufman, L., \& Rock, I. (1962b). The moon illusion: II. Science, 136, 1023-1031.

Koenderink, J. J. (2001). On seeing clearly. Perception, 30, 525-530.

Koenderink, J. J., van Doorn, A. J., \& Lappin, J. S. (2000). Direct measurement of the curvature of visual space. Perception, 29, 69-79.

LapPIN, J. S., \& AhLström, U. B. (1994). On the scaling of visual space from motion - in response to Pizlo and Salach-Golyska. Perception \& Psychophysics, 55, 235-242.

LAPPIN, J. S., \& CRAFT, W. D. (2000). Foundations of spatial vision: From retinal images to perceived shapes. Psychological Review, 107, 6-38.

Lappin, J. S., Donnelly, M. P., \& KoJima, H. (2001). Coherence of early motion signals. Vision Research, 41, 1631-1644.

LAPPIN, J. S., \& FUQUA, M. A. (1983). Accurate visual measurement of three-dimensional moving patterns. Science, 221, 480-481.

LapPIN, J. S., \& Love, S. R. (1992). Planar motion permits perception of metric structure in stereopsis. Perception \& Psychophysics, 51, 86102.

Le Grand, Y. (1967). Form and space vision (M. Millodot \& G. G. Heath, Trans.). Bloomington: Indiana University Press. (Original work published 1956)

LEVI, D. M., \& KLEIN, S. A. (1992). “Weber's law” for position: The role of spatial frequency and eccentricity. Vision Research, 32, 2235-2250.

Loomis, J. M., Da Silva, J. A., Fujita, N., \& Fukusima, S. S. (1992). Visual space perception and visually directed action. Journal of Experimental Psychology: Human Perception \& Performance, 18, 906-921.

Loomis, J. M., Da Silva, J. A., Philbeck, J. W., \& Fukusima, S. S. (1996). Visual perception of location and distance. Current Directions in Psychological Science, 5, 72-77.

MaCLeOD, D. I. A., \& Willen, J. D. (1995). Is there a visual space? In R. D. Luce, M. D'Zmura, D. Hoffman, G. J. Iverson, \& A. K. Romney (Eds.), Geometric representations of perceptual phenomena: Papers in honor of Tarow Indow on his 70th birthday (pp. 47-60). Hillsdale, NJ: Erlbaum.

Minnaert, M. G. J. (1993). Light and color in the outdoors (L. Seymour, Trans.). New York: Springer.

Norman, J. F., Lappin, J. S., \& Norman, H. F. (2000). The perception of length on curved and flat surfaces. Perception \& Psychophysics, 62, 1133-1145.

Norman, J. F., \& TodD, J. T. (1993). The perceptual analysis of structure from motion for rotating objects undergoing affine stretching transformations. Perception \& Psychophysics, 53, 279-291.

Norman, J. F., Todd, J. T., Perotti, V. J., \& Tittle, J. S. (1996). The visual perception of three-dimensional length. Journal of Experimental Psychology: Human Perception \& Performance, 22, 173-186.

Purdy, J., \& GibSON, E. J. (1955). Distance judgment by the method of fractionation. Journal of Experimental Psychology, 50, 374-380.

Riener, C. R., Witt, J. K., Stefanucci, J. K., \& Proffitt, D. R. (2005). Seeing beyond the target: An effect of environmental context on distance perception [Abstract]. Journal of Vision, 5, 195a. Available at journalofvision.org/5/8, doi:10.1167/5.8.195.

Rieser, J. J., Ashmead, D. H., Talor, C. R., \& Youngquist, G. A. (1990). Visual perception and the guidance of locomotion without vision to previously seen targets. Perception, 19, 675-689.

Rieser, J. J., Holman, K., Cummins, P., Weingarten, F., \& Ridley, C. (2004). Similarities in bipedal, bimanual, and quadripedal locomotion: Evidence for a unified locomotor action system. Abstracts of the Psychonomic Society, 9, 5.

Rieser, J. J., Pick, H. L., Jr., Ashmead, D. A., \& Garing, A. (1995). The calibration of human locomotion and models of perceptual-motor organization. Journal of Experimental Psychology: Human Perception \& Performance, 21, 480-497.

SEDGWICK, H. A. (1986). Space perception. In K. R. Boff, L. Kaufman, \& J. P. Thomas (Eds.), Handbook of perception and human performance (Vol. 1, pp. 21-1-21-57). New York: Wiley.

SinaI, M. J., OoI, T. L., \& He, Z. J. (1998). Terrain influences the accurate judgement of distance. Nature, 395, 497-500.

SupPES, P. (1995). Some foundational problems in the theory of visual space. In R. D. Luce, M. D’Zmura, D. D. Hoffman, G. J. Iverson, \& A. K. Romney (Eds.), Geometric representations of perceptual phenomena: Papers in honor of Tarow Indow on his 70th birthday (pp. 3745). Hillsdale, NJ: Erlbaum.

Suppes, P., Krantz, D. M., Luce, R. D., \& Tversky, A. (1989). Foundations of measurement: Vol. 2. Geometrical, threshold, and probabilistic representations. San Diego: Academic Press.

Thouless, R. H. (1931). Phenomenal regression to the real object: I. British Journal of Psychology, 21, 339-359.

TodD, J. T., \& Norman, J. F. (2003). The visual perception of 3-D shape from multiple cues: Are observers capable of perceiving metric structure? Perception \& Psychophysics, 65, 31-47.

ToYE, R. C. (1986). The effect of viewing position on the perceived layout of space. Perception \& Psychophysics, 40, 85-92.

Turvey, M. T. (2004). Space (and its perception): The first and final frontier. Ecological Psychology, 16, 25-29.

Wagner, M. (1985). The metric of visual space. Perception \& Psychophysics, 38, 483-495.

Wu, B., OoI, T. L., \& He, Z. J. (2004). Perceiving distance accurately by a directional process of integrating ground information. Nature, 428, 73-77.

\section{NOTES}

1. A fundamentally different prediction about visual scaling of space from optic flow is also plausible, based on the congruence of objects in different positions at different times: If $A$ and $B$ are two stationary objects at image positions $a$ and $b$ in the sagittal plane, and if the image of $A$ moves from $a$ to $b$ at the same time that $B$ moves from $b$ to $c$ during an observer's translation, the distance from $a$ to $b$ equals that from $b$ to $c$. Thus, vision might possibly achieve veridical scaling of space from locomotion. Lappin and Love (1992) and Lappin and Ahlström (1994) showed both theoretically and experimentally that under certain restricted conditions, this measurement procedure can yield accurate perception of three-dimensional metric structure from motion.

2. If the observers had used such cognitive strategies, even unconsciously, the environmental context effects probably would have differed from those we found. Both constant and variable errors should have been smaller in the hall and lobby than on the open lawn, but accuracy was lowest in the lobby and precision was lowest in the hall. We were unable to identify the specific cues that guided these judgments, either by our own observations or by questioning the participants. The general opinion seemed to be simply that the judged midpoint looked correct. 
3. For 7 of the observers, the heights of the adjustment and target persons were $6 \mathrm{ft}$ and $5 \mathrm{ft} 5 \mathrm{in}$., respectively. For the remaining observer, both adjustment and target persons were approximately $6 \mathrm{ft}$ tall. Additional checks with other experimenters and other observers found that the relative heights of the two experimenters had no discernible influence.

4. In fact, they were so persistent that we were motivated to check the measuring devices against another standard in each setting.

5. This numerical description is merely pragmatic, not intended as a theoretically valid interval scale of perceived distance. The finding that these numbers yielded approximately normal distributions suggests that this was a plausible description. Interpretation of the results, however, does not depend on assumptions about the specific numerical nature of this scale.
6. Le Grand (1956/1967) suggested that such effects might be attributable to the nonlinear decrease in binocular disparity with increasing depth. The idea is common in the classical literature that binocular disparity is a major determinant of the scale of visual space. If binocular disparity is a principal basis for perceived distances, however, the predicted result would seem to be foreshortening, rather than antiforeshortening. In addition, both the accuracy and the precision of binocularly based spatial judgments would be predicted to increase with the presence and spatial regularity of other environmental objects, but our results contradict this prediction as well.

(Manuscript received January 11, 2005; revision accepted for publication July 12, 2005.) 